\title{
Glinical usefulness of intravenous constant rate infusion of fentanyl and medetomidine under sevoflurane anesthesia in Thoroughbred racehorses undergoing internal fixation surgery
}

\author{
Fumiaki MIZOBE $^{1 *}$, Ai WAKUNO ${ }^{1}$, Jun OKADA ${ }^{1}$, Tasuku OTSUKA ${ }^{1}$, Yuhiro ISHIKAWA \\ and Shinjiro KURIMOTO ${ }^{1}$ \\ ${ }^{1}$ Racehorse Hospital, Ritto Training Center, Japan Racing Association, Shiga 520-3085, Japan
}

\begin{abstract}
A total of 20 racehorses with longitudinal fractures underwent internal fixation surgery under sevoflurane anesthesia combined with infusion of medetomidine ( $3 \mu \mathrm{g} / \mathrm{kg} / \mathrm{hr}$ ) alone (10 horses, group M) or medetomidine and fentanyl (7 $\mu \mathrm{g} / \mathrm{kg} / \mathrm{hr}$ ) (10 horses, group FM). In group $F M$, the end-tidal sevoflurane concentration during surgery was maintained significantly lower than in group $M(2.8-2.9 \%$ for group $M$ vs. $2.2-2.6 \%$ for group $F M, P<0.01)$. The mean arterial blood pressure was maintained over $70 \mathrm{mmHg}$ using dobutamine infusion (group $M, 0.36-0.54 \mu \mathrm{g} / \mathrm{kg} / \mathrm{min}$; group FM, 0.27-0.65 $\mu \mathrm{g} / \mathrm{kg} / \mathrm{min}$ ), and the recovery qualities were clinically acceptable in both groups. In conclusion, coadministration of fentanyl and medetomidine by constant rate infusion may be a clinically useful intraoperative anesthetic adjunct for horses to reduce the requirement of sevoflurane when they undergo orthopedic surgery.
\end{abstract}

Key words: fentanyl, medetomidine, racehorse, sevoflurane

\author{
J. Equine Sci. \\ Vol. 28, No. 4 \\ pp. $143-147,2017$
}

In equine anesthesia, sevoflurane is a commonly used volatile anesthetic agent characterized by rapid induction, easy control of anesthetic depth, and rapid recovery because of its low blood solubility [1]. Recently, with an aim to minimize the cardiopulmonary depressant effect caused by volatile anesthetic agents, several balanced anesthetic techniques have been proposed [17]. Constant rate infusion (CRI) of an $\alpha_{2}$ - adrenoceptor agonist is reportedly beneficial in reducing the amount of volatile anesthetics requirement for its potent sedative and analgesic effects [3]. A binding study in the rat brain indicated that the $\alpha_{2} / \alpha_{1}$ selectivity ratios would be $1,620,260$, and 160 for medetomidine, detomidine, and xylazine, respectively [18], and a recent study in horses undergoing surgery demonstrated a significant reduction in sevoflurane requirement during surgery [16]. Fentanyl is a synthetic $\mu$-opioid receptor agonist of the 4-anilinopiperidine series and is known to

Received: February 2, 2017

Accepted: August 18, 2017

*Corresponding author. e-mail: Fumiaki_Mizobe@jra.go.jp (C)2017 Japanese Society of Equine Science

This is an open-access article distributed under the terms of the Creative Commons Attribution Non-Commercial No Derivatives (by-nc-nd) License. (CC-BY-NC-ND 4.0: https://creativecommons.org/licenses/ by-nc-nd/4.0/) provide strong analgesic effect [12]. Recent investigations have demonstrated that balanced anesthesia with fentanyl provides perioperative analgesia and improves hemodynamics by minimizing the necessary inhalation concentration of anesthetic agents $[10,15]$. On the other hand, there has been a debate about the use of fentanyl in horses as an intraoperative anesthetic adjunct not just because of its cost and differences in $\mu$-opioid receptor affinity between species [5] but also because fentanyl is a legal control drug as narcotics in many countries including Japan. Importantly, it has been suggested that the analgesic effects of opioids and $\alpha_{2}$-agonists can synergize when co-administered, and therefore the interactions are potentially beneficial clinically [2]. Further, CRI of an $\alpha_{2}$-agonist would be expected to prevent perioperative excitation potentially caused by opioids.

To the best of the authors' knowledge, little has been reported on the clinical efficacy of co-administration of fentanyl and medetomidine in Thoroughbred racehorses undergoing orthopedic surgery, which could involve serious pain and stress. The purpose of the present study was to assess the clinical usefulness of fentanyl-medetomidine CRI under sevoflurane anesthesia.

Twenty Thoroughbred racehorses ( 8 females and 12 males, $3.4 \pm 1.7$ years old) weighing 414 to $520 \mathrm{~kg}$ (465 
$\pm 30 \mathrm{~kg}$ ) with longitudinal fractures underwent internal fixation surgery within 3 days after the development of the fractures. Fracture characteristics were as follows: sagittal fractures of the proximal phalanx ( 8 horses) and condylar fractures of the third metacarpus/metatarsus (12 horses). These horses were assigned randomly to group $\mathrm{M}$ or group FM. The 10 horses assigned to group $\mathrm{M}$ underwent surgery with sevoflurane together with medetomidine CRI, whereas the 10 horses assigned to group FM were maintained with sevoflurane in combination with fentanyl-medetomidine CRI.

The preoperative statuses of all horses were classified as Class I according to the American Society of Anesthesiologists because no abnormalities were found in any of the horses in the results of preanesthetic blood examination and electrocardiography. Food was withheld from horses before the operation, but water was freely accessible. A 14-G catheter was placed in the external jugular vein. All horses were premedicated with medetomidine (6.0-7.5 $\mu \mathrm{g} / \mathrm{kg} / \mathrm{IV}$; Domitor, Nippon Zenyaku Kogyo Co., Ltd., Fukushima, Japan) and midazolam ( $20 \mu \mathrm{g} / \mathrm{kg} / \mathrm{IV}$; Dormicum, Astellas Pharma Inc., Tokyo, Japan). Anesthesia was induced by a rapid injection of $5 \%$ guaifenesin $(600-800 \mathrm{~m} / / \mathrm{head} / \mathrm{IV}$; $5 \%$ Guaifenesin, Shinyo Pure Chemicals Co., Ltd., Osaka, Japan) containing thiopental sodium $(2.0 \mathrm{mg} / \mathrm{head} / \mathrm{IV}$; Ravonal, Mitsubishi Tanabe Pharma Corp., Osaka, Japan). After induction of anesthesia, the horses were intubated endotracheally and positioned in lateral recumbency on a padded surgical table. Anesthesia was maintained with sevoflurane (Sevofrane, Maruishi Pharmaceutical Co., Ltd., Osaka, Japan) and oxygen (approximately $5 \mathrm{l} / \mathrm{min}$ ), and the horses were ventilated using intermittent positive pressure ventilation (MOK 94, Silver Medical Co., Tokyo, Japan) with a peak airway pressure of $25 \mathrm{cmH}_{2} \mathrm{O}$ to maintain the arterial carbon dioxide tension $\left(\mathrm{PaCO}_{2}\right)$ between 45 and 55 $\mathrm{mmHg}$. A base-apex lead electrocardiogram was used to monitor heart rate (HR) and cardiac rhythm.

A 20-gauge catheter was placed in the facial artery for measurement of systemic arterial blood pressure and for arterial blood sample collection. Arterial blood pressures were measured directly through the catheter by a transducer system (Biotranskit BTK-BBS-4812, Biosensors Japan Co., Ltd., Tokyo, Japan). Lactated Ringer's solution (Hartmann's solution pH8, Nipro Corp., Osaka, Japan) was infused at a rate of approximately $10 \mathrm{~m} / / \mathrm{kg} / \mathrm{hr}$ during anesthesia. Dobutamine (Dobutrex, Shionogi \& Co., Ltd., Osaka, Japan) was infused $(0.1-1.0 \mu \mathrm{g} / \mathrm{kg} / \mathrm{min})$ throughout anesthesia to maintain a mean arterial blood pressure (MAP) between 60 and $80 \mathrm{mmHg}$. Respiratory gas was collected continuously from the circuit end of the endotracheal tube, and the end-tidal sevoflurane concentration (ETSEVO) was determined by infrared absorption. The ETSEVO was recorded throughout anesthesia, and HR, systolic arterial blood pressure (SAP), diastolic arterial blood pressure (DAP), and MAP were recorded every $5 \mathrm{~min}$ by an anesthesia monitoring system (BP608, Omron Colin Co., Ltd., Tokyo, Japan). Arterial blood samples were collected every $15 \mathrm{~min}$, and $\mathrm{PaCO}_{2}$, arterial oxygen tension $\left(\mathrm{PaO}_{2}\right)$, and $\mathrm{pH}$ were immediately analyzed by a blood gas analyzer (ABL800 FLEX, Radiometer K.K., Tokyo, Japan).

The ETSEVO was adjusted to reach $2.8 \%$ within 15 min after induction of anesthesia. Thereafter, medetomidine CRI at the rate of $3 \mu \mathrm{g} / \mathrm{kg} / \mathrm{hr}$ was started using a computer-driven infusion pump (IVAC, Alaris Medical Systems, San Diego, CA, U.S.A.) and continued until the end of the operation. Thirty min after induction, the loading dose of fentanyl $(4.0 \mu \mathrm{g} / \mathrm{kg}$; Fentanyl, Daiichi Sankyo Co., Ltd., Tokyo, Japan) was administered intravenously over $15 \mathrm{~min}$ for the horses assigned to group FM. Following administration of the loading dose, the maintenance CRI dose of fentanyl (7 $\mu \mathrm{g} / \mathrm{kg} / \mathrm{hr}$ ) was administered throughout the operation. The surgical procedure was initiated $45 \mathrm{~min}$ after induction. Internal fixation surgery was carried out using screws in lag fashion and conventional AO instruments (Synthes, Paoli, PA, U.S.A.). The depth of anesthesia was assessed subjectively by at least two experienced anesthetists based on vital signs such as palpebral reflex, eye position, nystagmus, and cardiovascular status against surgical stimuli. The ETSEVO was adjusted to an adequate level for the surgical procedure until the end of anesthesia. The anesthetic depth was judged to be light if movement, brisk palpebral response, spontaneous nystagmus, or a sudden change of cardiovascular parameters was observed.

During recovery, all horses were assisted with either ropes or a large animal sling, and medetomidine $(1 \mu \mathrm{g} /$ $\mathrm{kg}$ ) was administered when necessary. Postoperatively, the horses received intravenous regional limb perfusion of amikacin (AMIKACIN Sulphate for Injection $200 \mathrm{mg}$ "Nichiiko", Nichiiko Co., Ltd., Toyama, Japan). Briefly, the cephalic vein on the affected limb was isolated using a tourniquet. Thereafter, $1 \mathrm{~g}$ of amikacin diluted in $40 \mathrm{ml}$ of saline was injected through a 22-gauge butterfly catheter placed in the cephalic vein. The tourniquet was removed after $30 \mathrm{~min}$. In addition, $1.0 \mathrm{mg} / \mathrm{kg} / \mathrm{IV}$ of flunixin meglumine (Banamine injection 5\%, DS Pharma Animal Health Co., Ltd., Osaka, Japan) was administered once daily for 5 days following surgery.

Data were analyzed for differences between administration drug and time by two-way repeated-measures analysis of variance tests, and pairwise comparisons were made by use of the Tukey-Kramer test. For statistical analysis of cardiopulmonary values, Dunnett's test was applied when a main effect was found only within time. Values are given as means $\pm \mathrm{SD}$, and statistical significance was set at $P<0.05$. 
The total anesthesia time was $139 \pm 37 \mathrm{~min}$ in group FM and $129 \pm 28 \mathrm{~min}$ in group M. The mean time taken from the end of anesthesia to standing was $60.0 \pm 14.9 \mathrm{~min}$ in group FM and $65.7 \pm 8.8 \mathrm{~min}$ in group M. The changes in ETSEVO during surgery are shown in Fig. 1. The values were significantly lower in group FM $(2.2-2.6 \%)$ than in group M (2.8-2.9\%, $P<0.01)$. Also, the ETSEVO decreased over time significantly from $2.6 \pm 0.1$ to $2.2 \pm 0.1 \%$ in group FM $(P<0.01)$. There was significant interaction between time and drug $(P<0.01)$. The cardiopulmonary values during the operations are shown in Table 1. The MAP values were maintained over $70 \mathrm{mmHg}$ during the operations in all horses, and there were no significant differences in mean dobutamine infusion rate between group FM (0.27-0.65 $\mu \mathrm{g} / \mathrm{kg} / \mathrm{min})$ and group $\mathrm{M}(0.36-0.54 \mu \mathrm{g} / \mathrm{kg} / \mathrm{min})$. The MAP values increased over time significantly $(P<0.05)$, and the values at 30 and 45 min were significantly larger than at 0 min $(P<0.05)$. There were no significant main effects or interactions with respect to the values for HR, SAP, DAP, $\mathrm{PaCO}_{2}$, and $\mathrm{PaO}_{2}$. Behavior and clinical response during recovery were scored from G5 (excellent) to G1 (poor) according to a scoring system by Mama et al. [8]. In group FM, 7 horses were scored as G5, and 3 horses were scored as G4. In group M, 4 horses were scored as G5, and 6 horses were scored as G4. Medetomidine $(1 \mu \mathrm{g} / \mathrm{kg})$ was administered to 9 horses in each group. No apparent complications were observed after anesthesia in any of the horses.

In equine orthopedic surgery, perioperative pain management is important, as the adverse physiological response caused by pain and stress could lead to serious complications

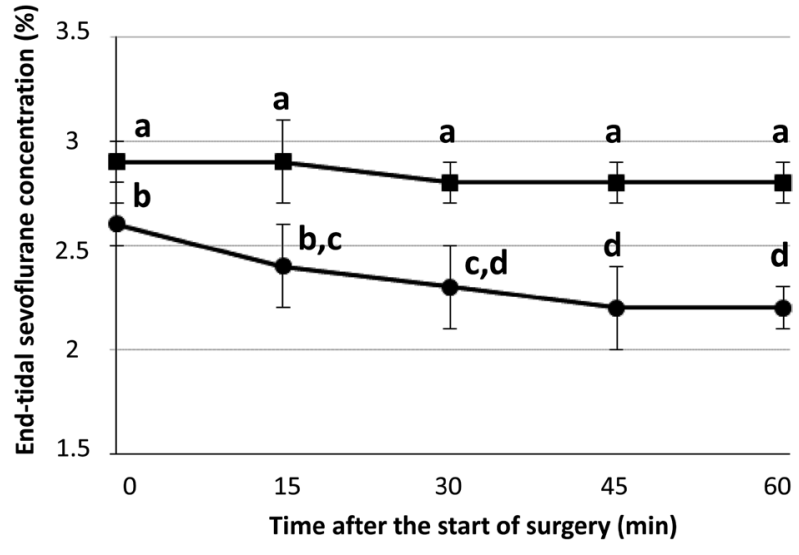

Fig. 1. Changes in end-tidal sevoflurane concentration during the operations in group M ( $)$ and group FM $(\bullet)$. Horses in group M were maintained with sevoflurane together with medetomidine CRI. Horses in group FM were maintained with sevoflurane in combination with fentanyl-medetomidine CRI. Data with the same superscript are not significantly different from each other $(P<0.01)$.

[20]. In the present study, flunixin meglumine, which is classified as a nonsteroidal anti-inflammatory drug (NSAID) was used to reduce pain postoperatively. In addition, the horses received $\alpha_{2}$-agonists and/or opioids during surgery as intraoperative anesthetic adjuncts, both of which could provide analgesia [17]. The horses were under the influence of these analgesics during recovery, and they were also under the influence of NSAIDs postoperatively. Presumably,

Table 1. Heart rate (HR); systolic (SAP), diastolic (DAP), and mean (MAP) arterial blood pressure; arterial carbon dioxide tension $\left(\mathrm{PaCO}_{2}\right)$; arterial oxygen tension $\left(\mathrm{PaO}_{2}\right)$; and dobutamine infusion rate during surgery in the horses of group FM and group $\mathrm{M}$

\begin{tabular}{|c|c|c|c|c|c|c|c|}
\hline & \multirow{2}{*}{ Variable } & \multirow{2}{*}{ Group } & \multicolumn{5}{|c|}{ Time after the start of surgery (min) } \\
\hline & & & 0 & 15 & 30 & 45 & 60 \\
\hline \multirow[t]{2}{*}{$\overline{\mathrm{HR}}$} & (beats/min) & FM & $33 \pm 2$ & $34 \pm 2$ & $34 \pm 2$ & $34 \pm 2$ & $33 \pm 2$ \\
\hline & & M & $36 \pm 2$ & $37 \pm 2$ & $37 \pm 2$ & $37 \pm 2$ & $37 \pm 2$ \\
\hline \multirow[t]{2}{*}{ SAP } & $(\mathrm{mmHg})$ & FM & $98 \pm 5$ & $101 \pm 6$ & $104 \pm 5$ & $103 \pm 6$ & $103 \pm 6$ \\
\hline & & M & $93 \pm 4$ & $100 \pm 4$ & $100 \pm 4$ & $101 \pm 4$ & $100 \pm 4$ \\
\hline \multirow[t]{2}{*}{ DAP } & $(\mathrm{mmHg})$ & FM & $57 \pm 1$ & $58 \pm 1$ & $59 \pm 1$ & $58 \pm 1$ & $59 \pm 2$ \\
\hline & & M & $56 \pm 3$ & $59 \pm 1$ & $59 \pm 2$ & $59 \pm 2$ & $57 \pm 2$ \\
\hline \multirow[t]{2}{*}{ MAP } & $(\mathrm{mmHg})$ & FM & $71 \pm 2$ & $74 \pm 1$ & $75 \pm 1$ & $74 \pm 2$ & $75 \pm 2$ \\
\hline & & M & $69 \pm 3$ & $73 \pm 1$ & $74 \pm 1$ & $74 \pm 1$ & $73 \pm 1$ \\
\hline \multirow[t]{2}{*}{$\mathrm{PaCO}_{2}$} & $(\mathrm{mmHg})$ & FM & $51 \pm 2$ & $52 \pm 1$ & $51 \pm 1$ & $50 \pm 1$ & $51 \pm 1$ \\
\hline & & M & $52 \pm 1$ & $50 \pm 1$ & $52 \pm 1$ & $52 \pm 0$ & $51 \pm 1$ \\
\hline \multirow[t]{2}{*}{$\mathrm{PaO}_{2}$} & $(\mathrm{mmHg})$ & FM & $496 \pm 13$ & $470 \pm 19$ & $485 \pm 15$ & $478 \pm 16$ & $488 \pm 22$ \\
\hline & & M & $470 \pm 28$ & $461 \pm 52$ & $478 \pm 31$ & $504 \pm 15$ & $468 \pm 38$ \\
\hline \multirow{2}{*}{\multicolumn{2}{|c|}{$\begin{array}{l}\text { Dobutamine infusion rate } \\
(\mu \mathrm{g} / \mathrm{kg} / \mathrm{min})\end{array}$}} & FM & $0.65 \pm 0.3$ & $0.60 \pm 0.3$ & $0.47 \pm 0.3$ & $0.39 \pm 0.3$ & $0.27 \pm 0.2$ \\
\hline & & M & $0.54 \pm 0.3$ & $0.40 \pm 0.2$ & $0.45 \pm 0.2$ & $0.36 \pm 0.2$ & $0.37 \pm 0.2$ \\
\hline
\end{tabular}

Data are presented as the mean \pm SD. Horses in group M were maintained with sevoflurane together with medetomidine CRI. Horses in group FM were maintained with sevoflurane in combination with fentanyl-medetomidine CRI. 
this may have contributed to the results indicating that there were no serious complications in any of the horses. It was considered that horses with moderate to severe pain should be treated with a multimodal analgesic approach as applied in the present study.

Inhaled anesthetics cause dose-related cardiopulmonary depression, which contributes to a high mortality rate [9]. Co-administration of analgesic drugs could reduce the amount of inhalation anesthetic required to maintain anesthesia by providing analgesia or altering consciousness. In equine anesthesia, the use of opioids, ketamine, $\alpha_{2}$-agonists, and lidocaine as intraoperative anesthetic adjuncts has been investigated [4]. In the investigation, it was shown that the minimum alveolar concentration (MAC) of inhalation anesthetics could be reduced by ketamine ( $3 \mathrm{mg} / \mathrm{kg} / \mathrm{hr}$ ) by up to $30 \%$. Likewise, infusion of lidocaine (3-6 mg/ $\mathrm{kg} / \mathrm{hr}$ ) could produce a dose-dependent reduction in the MAC of inhalation anesthetics, and it may also be expected to decrease postoperative ileus through its potential analgesic and antiinflammatory effects. On the other hand, these anesthetic adjuncts should be used with caution due to central nervous system excitation potentially caused by ketamine and ataxia induced by lidocaine, which could affect recovery quality. It has been shown that the MAC of inhalant agents could be reduced by opioids administration during surgery [10]. Further, a study by Thomasy et al. demonstrated a significant $(18 \%)$ reduction in the MAC of isoflurane after fentanyl administration, correlating to a mean plasma concentration of $13.31 \mathrm{ng} / \mathrm{m} l$ [15]. The loading and maintenance dose of fentanyl administered in the present study was determined in reference to this study, expecting that this would be adequate to induce a sevoflurane MAC sparing effect. Meanwhile, it has been suggested that fentanyl could be less effective in horses compared with other species, presumably due to the differences in $\mu$-opioid receptor affinity and distribution in the brain [5]. The infusion rate of medetomidine in the current study was determined on the basis of a previous report [16], in which an approximately $10 \%$ reduction in sevoflurane requirement was observed under arthroscopic surgery. In the current study, the sevoflurane requirement in group FM was reduced significantly, by approximately $18 \%$ compared with group M. It was presumed that the potent analgesic effect caused by fentanyl might have contributed to the reduction. The type of surgery and therefore level of surgical invasion were different between the current study and the above previous study, but the results of the current study indicate clinical efficacy of the balanced anesthesia techniques for cases with longitudinal fractures that could involve a certain level of pain and stress.

Sevoflurane is known to induce a dose-dependent decrease in hemodynamic variables in horses, and therefore reduction of sevoflurane should promote cardiovascular stability and improve perianesthetic care [14]. In the current study, the sevoflurane MAC sparing effect induced by co-administration of fentanyl and medetomidine was suggested to have contributed to maintenance of the MAP within the target values throughout the operation. A previous study showed that $\alpha_{2}$-agonists can reduce cardiac output due to the effect of increasing peripheral vascular resistance and afterload [19]. Opioids could potentially produce temporal effects on cardiovascular function due to central nervous system stimulation and subsequent increased sympathetic tone $[11,13]$. The significant reduction in sevoflurane requirement observed in group FM was speculated to provide support for cardiovascular function. Meanwhile, it has been suggested that cardiovascular function can also be influenced by several factors, including a horse's temperament, response to inotropic agents, and pain sensitivity [9]. All horses utilized in the present study had similar fracture characteristics, and therefore the levels of surgical invasion were speculated to be comparable between the groups. Further study using a larger population is warranted to clarify the effect of fentanyl-medetomidine CRI on cardiovascular function.

All horses in the current study recovered from anesthesia without any complications. Recovery from anesthesia is a potentially dangerous period for horses. Due to its potential central nervous system excitation [7], recovery from anesthesia in horses administered opioids could reportedly be dangerous [13]. In the present study, such adverse effects were not observed in group FM, and the recovery qualities were clinically acceptable in all horses. Presumably, medetomidine may have contributed to suppression of the excitation. It was shown that the fentanyl concentration declined rapidly after discontinuation of its CRI [15]. The dose adopted in the current study was presumed to be suitable to prevent excitation during recovery. Recovery quality could also be dependent on several other factors including the horse's physical status, duration of operation, and amount of anesthetic drugs administered [6]. Despite the fact that the mean total anesthesia time was over $2 \mathrm{hr}$ for both groups, particularly in group FM, ETSEVO was maintained low throughout the operations. Thus, sevoflurane was speculated to have been washed out from the body relatively faster after the horses were moved to the recovery room. It was presumed that this may have led to the safe recovery observed in the current study.

In conclusion, fentanyl-medetomidine CRI can be a clinically useful balanced anesthesia technique as an aid to sevoflurane anesthesia for Thoroughbred racehorses undergoing orthopedic surgery. 


\section{References}

1. Aida, H., Mizuno, Y., Hobo, S., Yoshida, K., and Fujinaga, T. 1996. Cardiovascular and pulmonary effects of sevoflurane anesthesia in horses. Vet. Surg. 25: 164-170. [Medline] [CrossRef]

2. Chabot-Doré, A.J., Schuster, D.J., Stone, L.S., and Wilcox, G.L. 2015. Analgesic synergy between opioid and $\alpha_{2}$-adrenoceptors. Br. J. Pharmacol. 172: 388-402. [Medline] [CrossRef]

3. Creighton, C.M., Lemke, K.A., Lamont, L.A., Horney, B.S., and Riley, C.B. 2012. Comparison of the effects of xylazine bolus versus medetomidine constant rate infusion on cardiopulmonary function and depth of anesthesia in horses anesthetized with isoflurane. J. Am. Vet. Med. Assoc. 240: 991-997. [Medline] [CrossRef]

4. Doherty, T., and Valverde, A. 2006. Management of sedation and anesthesia. pp. 206-259. In: Manual of Equine Anesthesia and Analgesia. (Doherty, T. and Valverde, A. eds.), Blackwell Publishing Ltd., Oxford.

5. Gozalo-Marcilla, M., Gasthuys, F., and Schauvliege, S. 2015. Partial intravenous anaesthesia in the horse: a review of intravenous agents used to supplement equine inhalation anaesthesia. Part 2: opioids and alpha-2 adrenoceptor agonists. Vet. Anaesth. Analg. 42: 1-16. [Medline] [CrossRef]

6. Hubbell, J.A. 1999. Recovery from anaesthesia in horses. Equine Vet. Educ. 11: 160-167. [CrossRef]

7. Kamerling, S.G., DeQuick, D.J., Weckman, T.J., and Tobin, T. 1985. Dose-related effects of fentanyl on autonomic and behavioral responses in performance horses. Gen. Pharmacol. 16: 253-258. [Medline] [CrossRef]

8. Mama, K.R., Steffey, E.P., and Pascoe, P.J. 1996. Evaluation of propofol for general anesthesia in premedicated horses. Am. J. Vet. Res. 57: 512-516. [Medline]

9. Muir, W.W., and Hubbell, J.A.E. 2009. Anesthetic-associated complications. pp. 397-417. In: Equine Anesthesia: Monitoring and Emergency Therapy, 2nd ed. (Muir, W.W. and Hubbell, J.A.E. eds.), Saunders Elsevier, St. Louis.

10. Ohta, M., Wakuno, A., Okada, J., Kodaira, K., Nagata, S., Ito, M., and Oku, K. 2010. Effects of intravenous fentanyl administration on end-tidal sevoflurane concentrations in thoroughbred racehorses undergoing orthopedic surgery. $J$. Vet. Med. Sci. 72: 1107-1111. [Medline] [CrossRef]
11. Pascoe, P.J., Steffey, E.P., Black, W.D., Claxton, J.M., Jacobs, J.R., and Woliner, M.J. 1993. Evaluation of the effect of alfentanil on the minimum alveolar concentration of halothane in horses. Am. J. Vet. Res. 54: 1327-1332. [Medline]

12. Scholz, J., Steinfath, M., and Schulz, M. 1996. Clinical pharmacokinetics of alfentanil, fentanyl and sufentanil. An update. Clin. Pharmacokinet. 31: 275-292. [Medline] [CrossRef]

13. Steffey, E.P., Eisele, J.H., and Baggot, J.D. 2003. Interactions of morphine and isoflurane in horses. Am. J. Vet. Res. 64: 166-175. [Medline] [CrossRef]

14. Steffey, E.P., Mama, K.R., Galey, F.D., Puschner, B., and Woliner, M.J. 2005. Effects of sevoflurane dose and mode of ventilation on cardiopulmonary function and blood biochemical variables in horses. Am. J. Vet. Res. 66: 606-614. [Medline] [CrossRef]

15. Thomasy, S.M., Steffey, E.P., Mama, K.R., Solano, A., and Stanley, S.D. 2006. The effects of i.v. fentanyl administration on the minimum alveolar concentration of isoflurane in horses. Br. J. Anaesth. 97: 232-237. [Medline] [CrossRef]

16. Tokushige, H., Ohta, M., Okano, A., Kuroda, T., Kakizaki, M., Ode, H., Aoki, M., Wakuno, A., and Kawasaki, K. 2015. Effects of medetomidine constant rate infusion on sevoflurane requirement, cardiopulmonary function, and recovery quality in thoroughbred racehorses undergoing arthroscopic surgery. J. Equine Vet. Sci. 35: 83-87. [CrossRef]

17. Valverde, A. 2013. Balanced anesthesia and constant-rate infusions in horses. Vet. Clin. North Am. Equine Pract. 29: 89-122. [Medline] [CrossRef]

18. Virtanen, R., Savola, J.M., Saano, V., and Nyman, L. 1988. Characterization of the selectivity, specificity and potency of medetomidine as an $\alpha_{2}$-adrenoceptor agonist. Eur. J. Pharmacol. 150: 9-14. [Medline] [CrossRef]

19. Yamashita, K., Tsubakishita, S., Futaok, S., Ueda, I., Hamaguchi, H., Seno, T., Katoh, S., Izumisawa, Y., Kotani, T., and Muir, W.W. 2000. Cardiovascular effects of medetomidine, detomidine and xylazine in horses. J. Vet. Med. Sci. 62: 1025-1032. [Medline] [CrossRef]

20. Young, S.S., and Taylor, P.M. 1993. Factors influencing the outcome of equine anaesthesia: a review of 1,314 cases. Equine Vet. J. 25: 147-151. [Medline] [CrossRef] 